\title{
Comparison between traditional and scientific irrigation scheduling practices for furrow irrigated potatoes (Solanum tuberosum L.) in Ethiopia
}

\author{
EB Geremew, JM Steyn* and JG Annandale \\ Department of Plant Production and Soil Science, University of Pretoria, Pretoria 0002, South Africa
}

Accepted 14 December 2007

\begin{abstract}
Traditional irrigation schemes constitute about $40 \%$ of the total irrigated land in Ethiopia. Despite this, the sector has been overlooked and not supported by improved water management technologies. A survey conducted on one of the schemes, Godino, indicated that farmers apply the same amount of water regardless of crop type and growth stage. In view of this, an experiment was established at the Debre-Zeit Research Centre in Ethiopia with the objective of comparing the performance of two traditional irrigation management practices to two scientific scheduling methods namely an Irrigation Calendar generated with the Soil Water Balance (SWB) model and a neutron probe (NP) based scheduling method. The four irrigation regimes were applied to furrow irrigated potatoes. Plant sampling for dry mass determination was undertaken on a weekly basis. Results of leaf, canopy and total dry matter, as well as fresh tuber yields, indicated that the NP and SWB schedules were superior to the traditional scheduling methods. Leaf dry matter was the most responsive parameter to irrigation treatments. The overall results revealed that traditional irrigation practices did not meet the full potato crop water requirements to ensure acceptable yield, which emphasized the need for introducing better and more efficient practices. Since the best performing treatment, NP, is capital and skills intensive, site specific SWB calendars, which performed similarly to NP and are simpler to use, are to be recommended for farmers at the Godino scheme.
\end{abstract}

Keywords: Furrow irrigation, irrigation scheduling, neutron probe, SWB model, irrigation calendars, water productivity, potato growth

*To whom correspondence should be addressed (E-mail: martin.steyn@up.ac.za)

\section{Introduction}

In Ethiopia, small-scale traditional irrigation schemes constitute about $40 \%$ of the total irrigated land area. Despite this, the sector has largely been overlooked by authorities and not supported through improved water management technologies. Due to land and water resource shortages and the need for food self-sufficiency in the region, it has become essential to improve the productivity of this sector. A recent survey conducted at Godino, one of the representative schemes, revealed that farmers apply irrigation water according to its availability, regardless of profile deficit, crop type and growth stage. This highlights the fact that scarce water resources are not being used optimally and emphasizes the potential for improved water productivity by implementing efficient irrigation management practices.

Potato (Solanum tuberosum L.) is one of the most important crops grown on the Godino scheme. Potatoes are shallow rooted and more sensitive to soil water stress than other deep rooted crops (Canada Saskatchewan Irrigation Diversification Centre (CSIDC), 2005; Tekalign \& Hammes, 2005a ; 2005b). Most of the potato root system is confined to the top $0.2-0.3$ $\mathrm{m}$ of the soil profile, although, depending on the soil type and available soil water, some roots may penetrate to a depth of $1 \mathrm{~m}$. In addition to its shallow root system, the complex physiological response to water stress makes potatoes sensitive to even moderate plant water deficits (Bradley et al., 2005). The major physiological responses of potatoes to water stress, next to stomatal closure, are reductions in leaf expansion, stem and tuber growth (Van Loon, 1981; Bradley et al., 2005). Potatoes are particularly sensitive to water stress during tuber initiation, early tuber development and tuber bulking (Jefferies, 1993; Juzl \& Stefl, 2002; Lahlou et al., 2003; Tourneux et al., 2003; Bradley et al., 2005).
The goal of irrigation management is to maintain the water level in the root zone within a range where crop yield and quality are not hampered due to either insufficient or excess water. For potatoes, soil water content in the root zone should not be allowed to drop below $65 \%$ of the available soil water storage between irrigations (King \& Stark, 2002).

Monitoring soil water in the crop root zone will allow better management of water applications to meet the requirements of the crop. However, direct measurement of soil water in the field is tedious and usually requires specialised equipment. Irrigation scheduling models can estimate how much water is needed and when best to apply it on different soil types and crops. Many water balance approaches have been used to estimate crop water availability and irrigation requirements. Most of the time, calculations are based on potential evapotranspiration values estimated by locally tested formulae or, at best, on the Penman generalised expression (Smith, 1992; Allen et al., 1998). The Soil Water Balance (SWB) model is a mechanistic, real-time, generic crop, soil water balance irrigation scheduling model (Annandale et al., 2000; Jovanovic et al., 2002). It gives a detailed description of the soil-plant-atmosphere continuum, making use of weather, soil and crop management data. The model has been tested extensively and found to give reliable estimates of water use for a wide range of crops (Annandale et al., 2000; Jovanovic et al., 2002; Geremew et al., 2007). As an alternative to real-time scheduling, SWB can also be used to generate Irrigation Calendars, using site-specific soil and management inputs and long-term weather data. The generated irrigation calendar guides the user on when to irrigate and how much water to apply (Annandale et al., 2005). This approach can be very useful to small-scale farmers, who may not have access to computers or the skill to use them. 
Wetting front detectors (WFD) are also another simple and affordable irrigation-scheduling tool that monitors the physical movement of water down the soil profile (Stirzaker, 2003; Stirzaker et al., 2004). It was suggested that the combined use of SWB and WFDs could provide a more useful recommendation to the user (Annandale et al., 2005). Detectors are usually placed in pairs at different soil depths. Recommended placement depths for flood are $20 \mathrm{~cm}$ for the shallow WFD and $50 \mathrm{~cm}$ for the deeper one. Deeper placement may be considered for infrequent irrigations or very long furrows (Stirzaker, 2007). If the detectors are rarely activated, the crop is likely to be under-irrigated. If both shallow and deep detectors regularly respond to irrigation, the crop is likely to be over-irrigated (Stirzaker, 2003; Stirzaker et al., 2004). This information can then be used to adjust the calendar recommendation up or downwards, if necessary.

An experiment with potato as test crop was established at the Debre-Zeit Research Centre in Ethiopia. The objective was to compare two commonly followed traditional irrigation regimes with two scientifically based irrigation management methods, namely SWB Irrigation Calendars (with WFD feedback) and soil water monitoring, using a neutron probe. The hypothesis was that the use of scientific irrigation scheduling methods could improve water use efficiency.

\section{Material and methods}

\section{Site description}

The study was conducted at the Debre-Zeit Agricultural Research Centre experimental farm from January to April 2005. The site is located at $8^{\circ} 44^{\prime} \mathrm{N}, 39^{\circ} 02^{\prime} \mathrm{E}$ at an altitude of $1900 \mathrm{~m}$. It receives an average annual rainfall of about 900 $\mathrm{mm}$, with the highest average monthly maximum temperature of $28^{\circ} \mathrm{C}$ in May and the lowest average minimum temperature of $9{ }^{\circ} \mathrm{C}$ in December. According to the data from the National Soil Laboratory Service (unpublished), the soil is classified as clay loam in texture, with a bulk density of 1.29 $\mathrm{Mg} \mathrm{m}^{-3}$, field capacity of $0.33 \mathrm{~kg} \mathrm{~kg}^{-1}$ and permanent wilting point of $0.18 \mathrm{~kg} \mathrm{~kg}^{-1}$, which gives a plant available water (PAW) of around $200 \mathrm{~mm} \mathrm{~m}^{-1}$.

\section{Field procedures}

The soil was thoroughly prepared using a mouldboard plough, levelled and ridged, to give a row spacing of $0.75 \mathrm{~m}$. Sprouted potato tubers (local variety Awash) were planted on 12 January 2005 at a spacing of $0.3 \mathrm{~m}$ within the row. Each plot consisted of six $5 \mathrm{~m}$ long rows. A ridge about $25 \mathrm{~cm}$ high was constructed around each plot to facilitate the even distribution of furrow applied water within the plot and to avoid water from flowing out of the plot. Fertilizers were applied according to recommended guidelines (W.G. Gebremedhin, 2003, HARC, Ethiopia). The crop received $110 \mathrm{~kg} \mathrm{ha}^{-1} \mathrm{~N}$ in a split application, half at planting and the rest 30 days later in the form of urea. The crop also received $92 \mathrm{~kg} \mathrm{ha}^{-1} \mathrm{P}$ as diammonium phosphate at planting. The experiment was arranged in a randomised complete block design (RCBD) with four replications. Since the soil was dry at planting, four weekly irrigations of $60 \mathrm{~mm}$ each were applied to all plots before treatments were imposed, to ensure uniform plant establishment. There was no obvious pest infestation, except for tuber moth at levels far below the threshold for chemical control. Three fungicide sprays were applied at fortnightly intervals for the control of early and late blight. Weeding and inter-row cultivations were performed by hand hoeing when deemed necessary.

\section{Irrigation treatments}

SWB treatment: The 29 year average daily maximum and minimum temperatures, as well as soil physical properties, planting date and irrigation management options were used as inputs to the SWB model (Jovanovic et al., 2002) to produce a site specific seasonal Irrigation Calendar. For the first part of the growing season (until about 40 days after planting (DAP)) an irrigation interval of once every five days was used, whereafter the interval was increased to once every seven days. Two WFDs were installed in each plot, one at 0.3 $\mathrm{m}$ soil depth (Shallow WFD) and the second at $0.5 \mathrm{~m}$ (Deep WFD). These depths were slightly deeper than the most recent recommendations (Stirzaker, 2007). The WFDs were used as feedback to decide whether the irrigation amount recommended by the SWB calendar needed upward or downward adjustment. Ideally, all shallow WFDs should respond after each irrigation event, while deep WFDs should only respond occasionally. A simple algorithm was used to decide when to adjust the recommended irrigation amount, depending on the number of shallow and deep WFDs responding after the previous irrigation event (Annandale et al., 2005). When the WFDs indicated under irrigation, the recommended amount for the next irrigation was increased by $20 \%$. On the other hand, when the detectors indicated over irrigation, the next irrigation amount was reduced by $20 \%$. The Farmer's Traditional Practice (FTP) was based on the average irrigation depth and interval practised by the Godino scheme farmers close to the experimental station. For this treatment 50 $\mathrm{mm}$ of water was applied once every 10 days. The Research Centre Practice (RCP) treatment used the average irrigation depth and interval as practised by the Debre-Zeit Agricultural Research Centre, namely $60 \mathrm{~mm}$ of irrigation applied every six days. In the fourth treatment, soil water content was monitored weekly using a Neutron Probe (NP), and the profile was refilled to field capacity. However, for the first part of the growing season (until about $50 \mathrm{DAP}$ ) the neutron probe instrument was not functional. During this period an amount of about $40 \mathrm{~mm}$ was applied every seven days, including rainfall.

\section{Data recorded}

Soil water content (WC) was measured with a neutron probe (Model 503DR CPN Hydroprobe, Campbell Pacific Nuclear, California, USA). The neutron probe was calibrated for the site and weekly readings were taken before irrigation. One access tube was installed in the middle of each plot and readings were taken to $1.2 \mathrm{~m}$ depth at $30 \mathrm{~cm}$ intervals. Furrowflood irrigation was used to irrigate the plots according to the treatments. Irrigation water was measured using a three-inch $(76.2 \mathrm{~mm})$ throat-width Parshall flume and the duration of irrigation was calculated according to equation 1 (Kandiah, 1981). The Parshall flume was installed at the entrance to the plot to minimize water loss during conveyance and distribution. 


$$
\mathrm{T}=\mathrm{AD} / 60 \mathrm{Q}
$$

where $\mathrm{T}=$ time in minutes, $\mathrm{A}=$ plot area $\left(\mathrm{m}^{2}\right), \mathrm{D}=$ application depth $(\mathrm{mm})$ and $\mathrm{Q}=$ discharge rate $\left(1 \mathrm{~s}^{-1}\right)$.

Fractional interception (FI) of photosynthetically active radiation (PAR) was measured weekly with a Decagon sunfleck ceptometer (Decagon, Pullman, WA, USA), making one reference reading above and 10 readings beneath each canopy. Growth analyses were carried out weekly by harvesting plant material from a $1 \mathrm{~m}^{2}$ representative surface area from each plot. Fresh mass was measured directly after sampling and separated into leaves, stems and tubers. Leaf area was measured on the fresh leaf samples, using a CI-202 leaf area meter (CID Inc., Vancouver, WA, USA). Dry masses were determined after drying samples in an oven at $60^{\circ} \mathrm{C}$ for four to five days. Phenological development was monitored for each treatment during the growing season. Weather data was obtained from a weather station located about $200 \mathrm{~m}$ from the experimental field. Irrigation water use efficiency (IWUE) was calculated for all treatments using the net seasonal irrigation plus rainfall amount during the growing period and the tuber yield obtained (equation 2):

$$
I W U E=\frac{F T Y}{(I+P+\Delta S W C)}
$$

where IWUE is the irrigation water use efficiency $\left(\mathrm{kg} \mathrm{ha}^{-1}\right.$ $\left.\mathrm{mm}^{-1}\right)$, FTY is the fresh tuber yield $\left(\mathrm{kg} \mathrm{ha}^{-1}\right)$, I is the total seasonal irrigation amount $(\mathrm{mm}), \mathrm{P}$ is the total amount of precipitation during the growing season $(\mathrm{mm})$ and $\triangle \mathrm{SWC}$ is the change in soil water content between the last and first day of crop growth $(\mathrm{mm})$.

\section{Statistical analysis}

Analysis of variance was performed, using the SAS system for Windows 2002, the SAS Institute 2002. Means were compared using the least significant difference (LSD) test at $\mathrm{P}=0.05$.

Table 1 Potato fresh tuber yield (FTY), average leaf dry mass (LDM), average canopy dry mass (CDM), average tuber dry mass (TDM), maximum leaf area index ( $\mathrm{LAI}$ ), average fractional interception (FI) of PAR and standard error of mean (SEM) for the irrigation treatments compared.

\begin{tabular}{lcccccc}
\hline \multicolumn{1}{c}{ Treatment } & FTY kg m $^{-2}$ & LDM kg m$^{-2}$ & $\mathrm{CDM} \mathrm{kg} \mathrm{m}^{-2}$ & TDM kg m$^{-2}$ & LAI m $^{2} \mathrm{~m}^{-2}$ & FI \\
\hline NP & $2.37 \mathrm{a}$ & $0.11 \mathrm{a}$ & $0.14 \mathrm{a}$ & $0.44 \mathrm{a}$ & $3.50 \mathrm{a}$ & $0.58 \mathrm{a}$ \\
SWB & $2.34 \mathrm{a}$ & $0.09 \mathrm{~b}$ & $0.12 \mathrm{~b}$ & $0.39 \mathrm{a}$ & $3.49 \mathrm{a}$ & $0.52 \mathrm{~b}$ \\
RCP & $2.14 \mathrm{ab}$ & $0.08 \mathrm{bc}$ & $0.10 \mathrm{bc}$ & $0.38 \mathrm{a}$ & $2.73 \mathrm{~b}$ & $0.43 \mathrm{c}$ \\
FTP & $1.79 \mathrm{~b}$ & $0.07 \mathrm{c}$ & $0.09 \mathrm{c}$ & $0.28 \mathrm{~b}$ & $2.55 \mathrm{~b}$ & $0.40 \mathrm{c}$ \\
SEM & 0.076 & 0.004 & 0.005 & 0.017 & 0.013 & 0.022 \\
\hline CV \% & 9.99 & 9.42 & 9.73 & 9.90 & 18.02 & 8.01 \\
\hline
\end{tabular}

Means followed by the same letter are not significantly different at $\mathrm{P}=0.05$

$\mathrm{NP}=$ Neutron Probe

$\mathrm{SWB}=$ Soil Water Balance

$\mathrm{RCP}=$ Research Centre Practice

FTP $=$ Farmers' Traditional Practice

\section{Results and discussion}

\section{Leaf area index $\left(\mathrm{m}^{2} \mathrm{~m}^{-2}\right)$}

Maximum leaf area index (LAI) obtained per treatment and the overall seasonal LAI trends are given in Table 1 and Figure 1. In general, potato yield and other agronomic parameters obtained for this experiment were relatively low compared to values achieved for temperate regions. Smith (1968) and Kooman et al. (1996) indicated that potato yields are usually lower in eastern and tropical Africa, compared to those obtained in temperate zones. Smith (1968) suggested that it could be attributed to the detrimental effects of shortday length and high air and soil temperatures. Photoperiod plays an important role in potatoes, as tuberisation is triggered when the day-length falls below a certain critical threshold. Under short day-length conditions, tubers are initiated much earlier than under long-day conditions, making tuberisation more abrupt and, consequently, leading to much faster maturity and lower tuber yields (Smith, 1968; Juzl \& Stefl, 2002).

Leaf area index (LAI) data revealed that the NP treatment for most of the growing season produced the highest LAI, followed closely by the SWB treatment (Figure 1). Significant

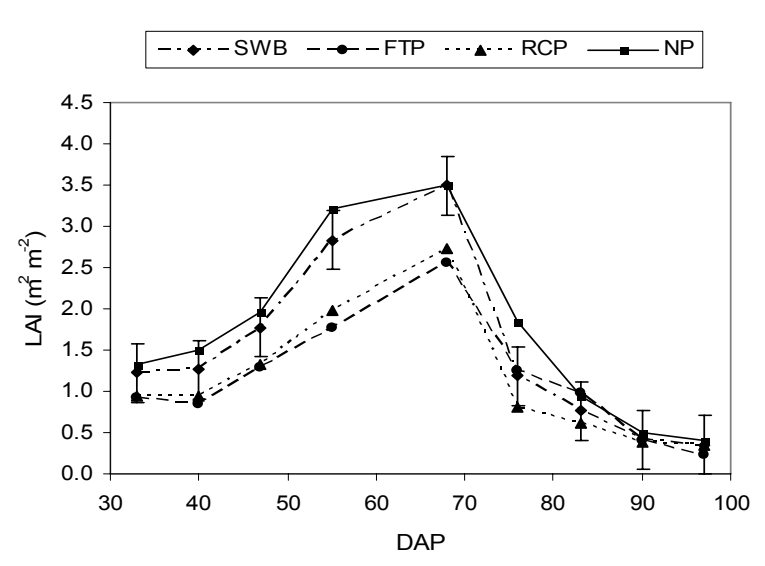

Figure 1 Leaf area index (LAI) for four irrigation treatments: Soil Water Balance (SWB), farmer traditional practice (FTP), research centre practice (RCP) and neutron probe (NP) treatments.

differences in LAI occurred between emergence and peak vegetative growth (about $68 \mathrm{DAP}$ ). The two traditional treatments, FTP and RCP, produced similar but lower LAI values, compared to the NP and SWB treatments (Figure 1). However, the NP and SWB treatments resulted in similar LAI val- 
ues, which were significantly higher than those of the two traditional practices. After reaching peak LAI values at about 68 DAP, the LAIs for all treatments declined drastically to reach similar minimum values at about 90 DAP. In general, the NP and SWB treatments were similar and consistently superior to the traditional treatments until about 76 DAP. Maximum LAI values obtained from the four irrigation regimes also confirmed that the two traditional practices were inferior $(\mathrm{P}>0.05)$ to the scientific scheduling practices (Table 1).

Leaf area index is one of the important parameters indicating potential crop growth performance and yield. Many researchers (Lahlou et al., 2003; Anita \& Giovanni, 2005; Bradley et al., 2005) agree that the maximum LAI achieved by a crop gives an indication of the total fraction of solar radiation interception, which determines photosynthetic production and tuber yield. For potatoes, a larger photosynthetically active leaf surface is important to maintain high tuber bulking rates for extended periods (Bradley et al., 2005), which is required for high tuber yields.

\section{Leaf dry mass (LDM), canopy dry mass (CDM) and total dry mass (TDM)}

Leaf dry mass yield is usually a good indicator of potential plant growth and yield. As indicated by David et al. (1983), Jefferies and MacKerron (1987) and Tourneux et al. (2003), tuber growth and development are dependent on the presence of sufficient foliage to produce the necessary assimilates and roots for adequate supply of water and nutrients to the canopy. In this experiment, seasonal LDM increment followed the same trend as that of LAI and reached maximum values at about 68 DAP, regardless of the irrigation treatment (Figure 2). Highest LDM was produced by the NP treatment, followed by SWB. LDMs started declining for all treatments after 68 DAP and converged to similar values from 76 DAP (Figure 2). This period coincided with the stage when maximum assimilate partitioning to the tubers occurred and when tubers gained substantial mass in a relatively short period of time.

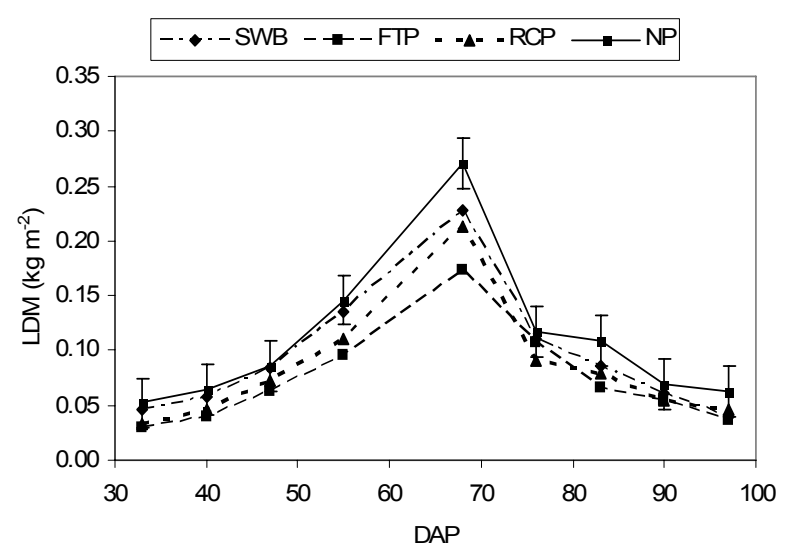

Figure 2 Leaf dry mass (LDM) for four irrigation treatments: Soil Water Balance (SWB), farmer traditional practice (FTP), research centre practice $(\mathrm{RCP})$ and neutron probe $(\mathrm{NP})$ treatments.

Canopy biomass production is proportional to the fraction of solar radiation intercepted, which influence photosynthetic production and final tuber yield. Juzl and Stefl (2002) found that potato cultivars with significantly higher canopy biomass also resulted in significantly higher tuber yields. Research has also proven that water shortage at any growth stage results in reduced canopy dry matter and tuber yield (Epstein \& Grant, 1973; MacKerron \& Jefferies, 1988; Deblonde \& Ledent, 2000; Juzl \& Stefl, 2002). The average LDM and CDM obtained in this experiment confirm these findings (Table 1). The NP treatment significantly out yielded $(\mathrm{P}<0.05)$ the other treatments, followed by SWB. For TDM, however, treatment FTP produced the lowest yield $(\mathrm{P}<0.05)$, while the other three treatments did not differ significantly from each other $(\mathrm{P}>0.05)$.

\section{Fresh tuber yield (FTY)}

Fresh tuber yield (FTY) followed the same trend as for above ground dry mass yield (CDM) and LAI during the growth period (Table 1). Hence, treatments NP and SWB resulted in highest fresh tuber yields, compared to the other treatments $(\mathrm{P}<0.05)$. Similar findings were also obtained by Deblonde and Ledent (2000), who reported that most agronomic parameters, photosynthetic production and yield were affected by levels of water supply. Tourneux et al. (2003) also stated that water stress slightly reduced leaf area index and canopy cover in all the genotypes they tested, and that final dry matter production was greatly affected.

In general, the NP and SWB treatments produced highest final fresh tuber yields, LDM, CDM and TDM, compared to the two traditional practices (RCP \& FTP) (Table 1). The fresh tuber yield obtained by FTP was inferior by $32 \%$ to that of NP and by $31 \%$ to that of SWB. Differences were statistically significant at $\mathrm{P}<0.05$ (Table 2). Irrigating less than the crop water requirements was primarily responsible for the reduction in LDM, which negatively affected CDM (Table 1) and consequently tuber yield.

\section{Fractional interception (FI)}

Fractional interception of PAR is an important indicator of biomass production and tuber yield (Williams et al., 1996; Lahlou et al., 2003). FI results (Table 1) show that the NP and SWB treatments had significantly higher canopy cover (FI) values $(\mathrm{P}<0.05)$, compared to the two traditional treatments, implying that they intercepted the highest average fractions of solar radiation. Lahlou et al. (2003) reported that the first manifestation of water shortage is a reduction in potato leaf size, resulting in a reduced amount of radiation intercepted, which finally leads to a decrease in tuber dry mass accumulation. The same authors further explained that reduced leaf growth and accelerated leaf senescence are common responses to water deficits and are adaptations of plants to water deficit. Deblonde and Ledent (2000) also reported that intercepted radiation was mostly influenced by the level of water application and to a lesser extent by other factors such as ambient conditions. Measured FI values over the growing season revealed a sharp increase in FI until 47 DAP, whereafter it levelled off and reached peak values at about 68 DAP (Figure 3). A gradual decline in FI was observed between 68 and 90 DAP, whereafter FI declined sharply. Treatments NP and SWB maintained the highest FI values throughout the growing season, while FTP had the lowest values. 
Table 2 Total seasonal water applied, tuber yield and irrigation water use efficiency (IWUE) for four irrigation treatments: re-filling to field capacity as per the neutron probe reading (NP), Soil Water Balance (SWB), research centre practice $(\mathrm{RCP})$ and farmers traditional practice (FTP) treatments.

\begin{tabular}{cccc}
\hline $\begin{array}{c}\text { Irrigation } \\
\text { Treatment }\end{array}$ & $\begin{array}{c}\text { Tuber yield } \\
\left(\mathrm{kg} \mathrm{ha}^{-1}\right)\end{array}$ & $\begin{array}{c}\text { Total water } \\
\text { applied }(\mathrm{mm})\end{array}$ & $\begin{array}{c}\text { IWUE } \\
\left(\mathrm{kg} \mathrm{ha}^{-1} \mathrm{~mm}^{-1}\right)\end{array}$ \\
\hline NP & $23700 \mathrm{a}$ & 631 & 37.6 \\
SWB & $23400 \mathrm{a}$ & 654 & 35.8 \\
RCP & $21400 \mathrm{~b}$ & 594 & 36.0 \\
FTP & $17900 \mathrm{~b}$ & 456 & 39.2 \\
\hline
\end{tabular}

Means followed by the same letter are not significantly different at $\mathrm{P}=0.05$

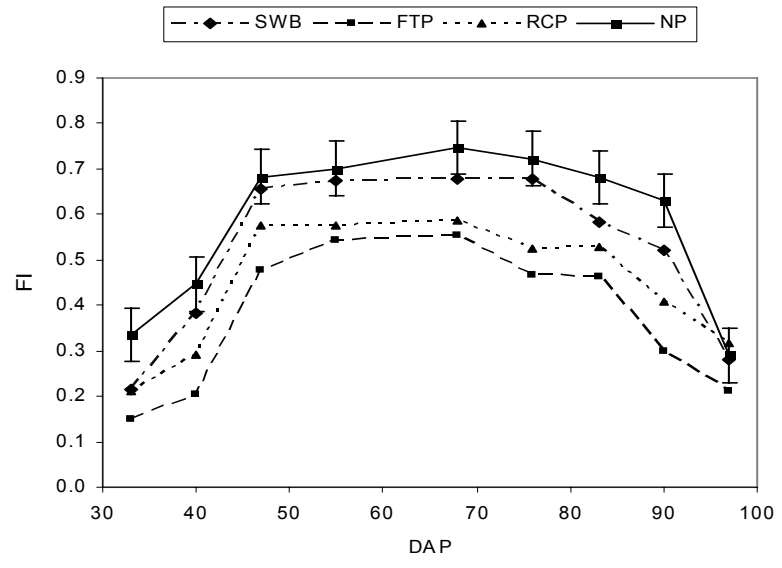

Figure 3 Fractional interception (FI) of the photosynthetically active radiation (PAR) for four irrigation treatments: Soil Water Balance (SWB), farmers traditional practice (FTP), research centre practice (RCP) and the neutron probe (NP) treatments.

\section{Irrigation Water Use and Irrigation Water Use Efficiency (IWUE)}

Difference in total water usage is one of the main reasons for yield variation in crops in general and potatoes in particular. For this experiment, irrigation water use for the different scheduling treatments ranged from $456 \mathrm{~mm}$ for FTP to 654 $\mathrm{mm}$ for SWB (Table 2). The treatment with highest total irrigation amount (SWB) resulted in the second highest tuber yield $(\mathrm{P}<0.05)$. Irrigation amounts recommended by the SWB calendar were often adjusted upwards by $20 \%$, due to the fact that WFDs responded rarely (data not presented). This most probably resulted in over irrigation of the SWB treatment at times, which could have resulted in leaching of nutrients and slightly lower tuber yields. The poor WFD response could possibly be attributed to too deep placement for the specific soil, which is known to reduce WFD sensitivity. The FTP treatment had lowest water use, but this resulted in the smallest canopy size and lowest tuber yield $(\mathrm{P}<0.05)$.

Irrigation water use efficiency (IWUE) gives the relationship between the quantity of water consumed ( $\mathrm{I}+\mathrm{P} \pm \Delta \mathrm{SWC}$ ) and yield or dry mass produced (Della Costa et al., 1997). Table 2 shows the calculated IWUEs expressed per fresh tuber yields obtained for each treatment. The results reveal that highest IWUE was obtained for the FTP treatment, followed by the NP treatment (Table 2). IWUEs did not vary much between treatments and ranged from $35.8 \mathrm{~kg} \mathrm{ha}^{-1} \mathrm{~mm}^{-1}$ for the SWB treatment to $39.2 \mathrm{~kg} \mathrm{ha}^{-1} \mathrm{~mm}^{-1}$ for the FTP treat- ment. The lower IWUE achieved by the SWB treatment can probably be explained by occasional over irrigation, as explained above. IWUE values obtained for all treatments are substantially lower as compared to the results obtained by other researchers (Islam et al., 1990; Onder et al., 2005). Onder et al. (2005) evaluated IWUE of potatoes under two irrigation regimes and obtained values that ranged from 66 to $114 \mathrm{~kg} \mathrm{ha}^{-1} \mathrm{~mm}^{-1}$. Similarly, Islam et al. (1990) evaluated potato water use efficiency. The low IWUEs recorded for this experiment could probably be attributed to the overall low irrigation efficiency of furrow flood irrigation, which is usually around $60 \%$. Water conveyance and application losses for flood are substantially higher, compared with other irrigation systems, such as sprinkler or drip irrigation. Furthermore, yields were much lower than those typically obtained from areas with temperate climates, combined with optimal management practices (Kooman et al., 1996). These authors argue that the low yielding potential of potatoes in the tropics and subtropics result from high temperatures and short day length conditions, to which most potato cultivars are not well adapted. The combined effects of low yields and high irrigation amounts finally culminated in the low IWUEs recorded. However, high IWUE on its own is not necessarily an indication of the best scheduling method. The findings of many research reports (Shimshi et al., 1983; Ferreira \& Carr, 2002; Yuan et al., 2003) usually conclude that the less water used, the higher the irrigation water use efficiency. Although the FTP treatment had a slightly higher IWUE than other treatments in our study, its tuber yield was $24 \%$ lower than that of the NP treatment, for example. Therefore, any of the other three irrigation strategies would make better use of resources (solar radiation, fertilizers and land) compared to the FTP treatment.

Figure 4 illustrates the soil water deficits measured just before each irrigation event during the growing season. From this, it is clear that the FTP treatment, which had the lowest seasonal water consumption and lowest final tuber yield (Table 2), also had the highest soil water deficits throughout the growing season. The low soil water deficit recorded for RCP on 64 DAP was due to a heavy rainfall event that occurred just after irrigating this particular treatment. Although soil water deficits for this treatment remained the lowest for the remainder of the growing season, it still had lower tuber yields than the SWB and NP treatments. The lower tuber yield recorded for RCP could probably be attributed to serious water stress earlier in the growing season, from which the crop could not fully recover. Although there is 
no soil water content data for the first part of the growing season to support this argument, the presence of early stress is confirmed by the lower LAI, LDM and CDM values recorded for RCP earlier in the growing season.

\section{Conclusions}

The potato water regime experiment conducted at Debre-Zeit,

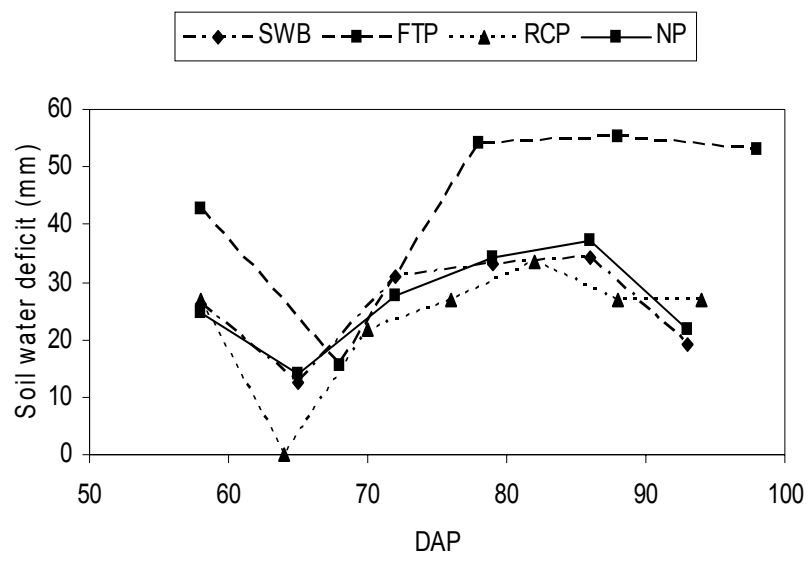

Figure 4 Soil water deficit to field capacity measured before irrigation for four irrigation treatments: Soil Water Balance (SWB), farmer traditional practice (FTP), research centre practice (RCP) and neutron probe (NP) treatments.

Ethiopia, indicated that the traditional water application regime practised by farmers was not adequate for high potato production. The results revealed that fresh tuber yield and other yield attributes (LDM, CDM \& FI) were significantly affected by the different irrigation scheduling methods. LDM and CDM were markedly reduced for the FTP and RCP treatments, with statistically significant $(\mathrm{P}<0.05)$ differences. Reduction in canopy size was mainly responsible for reduced interception of solar radiation (FI), which resulted in reduced dry matter accumulation and finally, lower tuber yields. Irrigation water use and IWUE results revealed that the FTP scheduling method had slightly higher applied water productivity, followed by the NP method. However, IWUE values of all treatments were similar, ranging from about 36 to $39 \mathrm{~kg}$ $\mathrm{ha}^{-1} \mathrm{~mm}^{-1}$ and therefore should not be the only parameter used to differentiate between scheduling methods, but tuber yield should also be considered. Although the FTP treatment had a slightly higher IWUE than other treatments, its tuber yield was substantially lower than that of the NP and SWB treatments. Therefore, any of the other three irrigation strategies can be considered better than the FTP treatment. Hence, it is suggested that the current watering practice at Godino irrigation scheme (FTP) be replaced by a more efficient water management technique, based on thorough scheduling. From the results obtained, NP and SWB performed best, taking yield components and fresh tuber yields into account. However, the adoption of NP scheduling at the Godino scheme would require skilled neutron probe users. Furthermore, this method is time-consuming and the equipment not affordable to individual farmers. Therefore, it is recommended that the SWB calendar scheduling method, which performed similarly to the NP method, be introduced to farmers at the Godino scheme. Extension staff at the adjacent Debre-Zeit Agricul- tural Research Centre could generate and supply farmers with site-specific SWB calendars for different soils, crops and planting dates commonly used by farmers on the scheme. This method is simple, but can have a substantial impact on the productivity on subsistence farmer irrigation schemes in Ethiopia.

\section{References}

ALLEN, R.G., PEREIRA, L.S., RAES, D. \& SMITH, M., 1998. Crop evapotranspiration: guidelines for computing crop water requirements, FAO irrigation and drainage paper 56. FAO- Food and Agriculture Organization of the United Nations, Rome.

ANITA, I. \& GIOVANNI, M., 2005. Physiological and growth response to moderate water deficit of off-season potatoes in a Mediterranean environment. Agric. Water Manage. 82, 193-209.

ANNANDALE, J.G., STEYN, J.M., BENADÉ, N., JOVANOVIC, N.Z. \& SOUNDY, P., 2005. Technology transfer of the Soil Water Balance (SWB) model as a user friendly irrigation scheduling tool. Report to the Water Research Commission by the Department of Plant Production and Soil Science, University of Pretoria, Pretoria 0002, South Africa. WRC Report No TT 251/05.

ANNANDALE, J.G., CAMPBELL, G.S., OLIVER, F.C. \& JOVANOVIC, N.Z., 2000. Predicting crop water uptake under full and deficit irrigation: an example using pea (Pisum sativum L. cv. Puget). Irrig. Sci. 19, 65-72.

BRADLEY, A., JEFFREY, K. \& STARK, C., 2005. Potato irrigation management. University of Idaho, Cooperative extension system, Bul. 789, 1-15.

CANADA SASKATCHEWAN IRRIGATION DIVERSIFICATION CENTRE (CSIDC), 2005. Irrigation scheduling for potatoes. Agriculture and Agri-Food Canada, 901 McKenzie St. S, Sol 2 NO.

DAVID, W., ELIAS, W., RONALD, F. \& VOSS, E., 1983. Growth and yield response of two potato cultivars to various levels of applied water. Irrig. Sci. 3, 211-222.

DEBLONDE, P. \& LEDENT, J.F., 2000. Effects of moderate drought conditions on crop growth parameters and earliness of six potato cultivars under field conditions. INRA, EDP sciences. Agronomie 20, 595-608.

DELLA COSTA, L., DELlE VEDOVE, G., GIANQUINTO, G., GIOVANARDI, R. \& PERESSOTTI, A., 1997. Yield water use efficiency and nitrogen uptake in potato: Influence of drought stress. Potato Res. 40, 19-34.

EPSTEIN, E. \& GRANT, W.J., 1973. Water stress of the potato plant under field conditions. Agron. J. 65, 400-404.

FERREIRA, T.C. \& CARR, M.K.V., 2002. Response of potatoes to irrigation and nitrogen in a hot, dry climate. I. Water use. Field Crops Res. 78, 51-64.

GEREMEW, E.B., STEYN, J.M. \& ANNANDALE, J.G., 2007. Evaluation of growth performance and dry matter partitioning of four processing potato (Solanum tuberosum) cultivars. N. Zea. J. Crop Hort. Sci. 35, 385-393.

ISLAM, T., SARKER, H., ALAM, J. \& RASHID, H., 1990. Water use and yield relationships of irrigated potato. Agric. Water Manage. 18, 173-179.

JEFFERIES, R.A., 1993. Use of a simulation model to assess possible strategies of drought tolerance in potato. Agric. Syst. 41, 93104.

JEFFERIES, R.A. \& MACKERRON, D.K.L., 1987. Aspects of the physiological basis of cultivar differences in yield of potato under drought and irrigated conditions. Potato Res. 30, 201-217.

JOVANOVIC, N.Z., ANNANDALE, J.G. \& BENNIE, A.T.P., 2002. Calibration and validation of the SWB irrigation scheduling model for soybean (Glycin max. L. Merr., indeterminate cv. Wayne). S. Afr. J. Plant Soil 19, 165-171. 
JUZL, M. \& STEFL, J.M., 2002. The effect of leaf area index on potato yield in soils contaminated by some heavy metals. Mendel University of Agriculture and Forestry in Brno, Czeck Republic, Rostlinna Vyroba. 48, 298-306.

KANDIAH, A., 1981. Guide for measurement of irrigation water using Parshall Flumes and siphons. Technical Bulletin No. 1, Melka Werer Research Station, Institute of Agricultural Research, Addis Ababa.

KING, B.A. \& STARK, J.C., 2002. Economic importance of irrigation management in potato production systems of Idaho. http:// www.uidaho.edu/aberdeen/econ_import.htm (Accessed 22 August 2007).

KOOMAN, P.L., FAHEM, M., TEGERA, P. \& HAVERKORT, A.J., 1996. Effects of climate on different potato genotypes 1. Radiation interception, total and tuber dry matter production. European J. Agron. 5, 193-205.

LAHLOU, O., OUATTAR, S. \& LEDENT, J.F., 2003. The effect of drought and cultivar on growth parameters, yield and yield components of potato. INRA EDP science. Agronomie 23, 257-268.

MACKERRON, D.K.L. \& JEFFERIES, R.A., 1988. The distribution of tuber sizes in droughted and irrigated crops of potato: I. Observations on the effect of water stress on graded yields from differing cultivars. Potato Res. 31, 269-278.

ONDER, S., CALISKAN, M.E., ONDER, D. \& CALISKAN, S., 2005. Different irrigation methods and water stress effects on potato yield and yield components. Agric. Water Manage. 73, 7386.

SAS system for Windows, 2002. The SAS Institute Inc., Cary, NC, USA, SAS Proprietary Software, Version 9.00.

SHIMSHI, D., SHALHEVET, J. \& MEIR, T., 1983. Irrigation regime effects on some physiological response of potato. Agron. J. 75, 262-267.

SMITH, O., 1968. Potatoes: Production, Storing and Processing. The Avi Publishing Company Inc. New York.
SMITH, M., 1992. CROPWAT- A computer program for irrigation planning and management. FAO Irrigation and Drainage Paper No. 46. FAO, Rome, Italy.

STIRZAKER, R.J., 2003. When to turn the water off: scheduling micro-irrigation with a wetting front detector. Irrig. Sci. 22, 177185.

STIRZAKER, R.J., 2007. Full Stop ${ }^{\mathrm{TM}}$ wetting front detector. http:// www.fullstop.com.au/ (Accessed 10 October 2007)

STIRZAKER, R.J., STEVENS, J., ANNANDALE, J., MAEKO, T., STEYN, M., MPANDELI, S., MAUROBANE, W., NKGAPELE, J. \& JOVANOVIC, N., 2004. Building capacity in irrigation management with wetting front detectors. Report to the Water Research Commission, WRC report No. TT 230/04, South Africa.

TEKALIGN, T. \& HAMMES, P.S., 2005a. Growth response of potato (Solanum tuberosum L.) grown in a hot tropical lowland to applied paclobutrazol: I. Shoot attributes, assimilate production and allocation. N. Zea. J. Crop Hort. Sci. 33, 35-42.

TEKALIGN, T. \& HAMMES, P.S., 2005b. Growth and productivity of potato as influenced by cultivar and reproductive growth: II. Growth analysis, tuber yield and quality. Sci. Hort. 105, 13-27

TOURNEUX, C., DEVAUX, A., CAMACHO M., MAMANI, P. \& LEDENT, J.F., 2003. Effect of water shortage on six potato genotypes in the highlands of Bolivia (I): morphological parameters, growth and yield. INRA, EDP Sciences, Agronomie 23, 169-179.

VAN LOON, C.D., 1981. The effect of water stress on potato growth, development, and yield. Am. Potato J. 58, 51-69.

WILLIAMS, J.H., NAGESWARA ROA, R.C., DOUGBEDJI, F. \& TALWAR, H.S., 1996. Radiation interception and modelling as an alterative to destructive samplings in crop growth measurements. Ann. Appl. Boil. 129, 151-160.

YUAN, B.Z., NISHIYANA, S. \& KANG, Y., 2003. Effect of different irrigation regimes on the growth and yield of drip-irrigated potato. Agric. Water Manage. 63, 153-167. 